\title{
Chemoprevention of 1,2-dimethylhydrazine-induced colonic preneoplastic lesions in Fischer rats by 6-methylsulfinylhexyl isothiocyanate, a wasabi derivative
}

\author{
TOSHIYA KUNO ${ }^{1,2}$, YOSHINOBU HIROSE ${ }^{1}$, YASUHIRO YAMADA ${ }^{1}$, KATSUMI IMAIDA $^{2}$, \\ KENJIRO TATEMATSU ${ }^{3}$, YUKIO MORI ${ }^{3}$ and HIDEKI MORI ${ }^{1}$ \\ ${ }^{1}$ Department of Tumor Pathology, Graduate School of Medicine, Gifu University, Gifu 501-1194; ${ }^{2}$ Onco-Pathology, \\ Department of Pathology and Host-Defense, Faculty of Medicine, Kagawa University, Kagawa 761-0793; \\ ${ }^{3}$ Institute of Biological Pharmacy, Gifu Pharmaceutical University, Gifu 502-8585, Japan
}

Received August 25, 2009; Accepted November 26, 2009

DOI: 10.3892/ol_00000048

\begin{abstract}
The preventive effects of dietary exposure to a wasabi derivative 6-methylsulfinylhexyl isothiocyanate (6-MSITC) during the initiation and post-initiation phases on the development of 1,2-dimethylhydrazine (DMH)-induced colonic aberrant crypt foci (ACF), and $\beta$-catenin-accumulated crypts (BCAC) were investigated in male F344 rats. To induce $\mathrm{ACF}$ and $\mathrm{BCAC}$, rats were given four weekly subcutaneous injections of $\mathrm{DMH}$ (40 mg/kg body weight). The rats also received diets containing 200 or 400 ppm 6-MSITC during the initiation or post-initiation phases. The experiment was terminated 12 weeks after the start. DMH exposure produced a substantial number of ACF $(323.8 \pm 69.7 /$ colon) and BCAC $\left(3.80 \pm 1.05 / \mathrm{cm}^{2}\right)$ at the end of the study. Dietary administration of 6-MSITC at a dose of $400 \mathrm{ppm}$ during the initiation phase caused a significant reduction in the total number of ACF $(52 \%$ reduction, $\mathrm{P}<0.0001)$, larger $\mathrm{ACF}$ (4 or more crypt $\mathrm{ACF})(58 \%$ reduction, $\mathrm{P}<0.001)$ and $\mathrm{BCAC}(76 \%$ reduction, $\mathrm{P}<0.00001)$. The dietary exposure to 6-MSITC significantly reduced the size (crypt multiplicity) of BCAC during both initiation and post-initiation treatment when compared to group 1 treated with DMH alone. Immunohistochemically, 6-MSITC administration lowered the proliferating cell nuclear antigen labeling index in ACF and BCAC. In addition, protein levels of hepatic cytochrome P-450 isozymes at $24 \mathrm{~h}$ after 6-MSITC exposure were significantly suppressed $(\mathrm{P}<0.01)$. The results indicated that 6-MSITC exerted chemopreventive effects in the present short-term colon carcinogenesis bioassay, through
\end{abstract}

Correspondence to: $\operatorname{Dr}$ Toshiya Kuno, Onco-Pathology, Department of Pathology and Host-Defense, Faculty of Medicine, Kagawa University, 1750-1 Ikenobe, Miki-cho, Kita-gun, Kagawa 761-0793, Japan

E-mail:kuno@med.kagawa-u.ac.jp

Key words: aberrant crypt foci, $\beta$-catenin accumulated crypts, 6-methylsulfinylhexyl isothiocyanate alterations in cell proliferation activity and drug metabolizing enzyme levels.

\section{Introduction}

Colorectal cancer is one of the leading causes of cancerrelated death worldwide and is therefore a major public health concern (1). Although the causes are not completely understood, dietary factors appear to be important (2). In a large number of epidemiological studies, increased consumption of vegetables and fruits have been consistently associated with a low risk of colorectal cancer (3-5).

For example, it was reported that cruciferous vegetables, and particularly broccoli consumption, are linked to a lowered risk of colon cancer, and the protective effects are particularly evident in individuals with the glutathione transferase M1 null genotype (6). Much attention has been focused on which dietary constituents play critical roles in cancer preventive actions, and with cruciferous vegetables the beneficial effects may be attributed, at least in part, to the high content of isothiocyanates (ITCs). ITCs are abundant in cruciferous vegetables such as broccoli, horseradish, mustard, watercress, cabbage or cauliflower. Interestingly, some of the purified products have been shown to possess potent anticarcinogenic properties in cell culture models as well as in experimental animal models. Inhibitory influence has been documented for rat lung, esophagus, mammary gland, liver, small intestine, colon and bladder tumorigenesis $(7,8)$. Although the ultimate causes of the preventive effects have yet to be defined in detail, enhanced detoxification of carcinogens (phase II enzyme activation) as well as blocking carcinogen activation (phase I enzyme inhibition) are presumably involved (9).

Various ITCs have been shown to inhibit cytochrome P450 (CYP) and increase the carcinogen excretion or detoxification by phase II detoxification enzymes such as glutathione S-transferase (GST) and NAD(P)H: quinone reductase (QR) (10-13). A typical Japanese condiment, wasabi (Wasabia japonica) was considered as a possible source of antimutagenic and anticancer agents $(14,15)$. An extract was found to reduce the growth of the human monoblastic leukemia cells by 
inducing apoptosis (16). One particular ingredient, 6-methylsulfinylhexyl isothiocyanate (6-MSITC), was found to inhibit cell proliferation in human breast cancer and melanoma cell lines (17). Morimitsu et al reported that 6-MSITC activates the ARE/Nrf2-dependent detoxification pathway, and oral administration resulted in the induction of hepatic GST and QR in mouse liver (18). Nrf-2 also regulated the detoxification enzyme, UDP-glucuronyltransferase (UDPGT), in the mouse (19).

The present bioassay, using rats, was conducted to determine whether dietary 6-MSITC can modulate carcinogen-induced colon carcinogenesis. Thus, the incidences of two different mucosal lesions, aberrant crypt foci (ACF) and $\beta$-catenin-accumulated crypts (BCAC) as surrogate endpoints in the place of tumors were evaluated. In addition, to assess whether 6-MSITC affects cell proliferation activity in colonic preneoplastic lesions, the proliferating cell nuclear antigen (PCNA) index was evaluated. Protein levels of CYP enzymes and the activity of UDPGT in the liver were also measured.

\section{Materials and methods}

Animals, chemicals and diets. All animal studies were carried out under the Regulations for Animal Experiments at Gifu University. Male F344 rats (Shizuoka Laboratory Animal Center, Shizuoka, Japan) aged 4 weeks were housed in wire cages (three or four rats per cage). The rats had free access to drinking water and diets, under controlled conditions of humidity $(50 \pm 10 \%)$, lighting (12-h light/dark cycle) and temperature $\left(23 \pm 2^{\circ} \mathrm{C}\right)$. The rats were quarantined for 7 days and then randomized into experimental and control groups. Powdered CE-2 (Clea Japan, Tokyo, Japan) diet was used as the basal diet throughout the study. 6-MSITC (purity >99\%) was kindly donated by Kinjirushi Co., Ltd. (Nagoya, Japan) and incorporated into the experimental diet at concentrations of 200 and $400 \mathrm{ppm}$. The diets were stored in a cold room $\left(4^{\circ} \mathrm{C}\right)$ until use. 1,2-Dimethylhydrazine $(\mathrm{DMH})$ was obtained from Tokyo Kasei Kogyo Co., Ltd. (Tokyo, Japan) and administered by subcutaneous (s.c.) injection $(40 \mathrm{mg} / \mathrm{kg})$ between 10:00 and 11:00 am to induce colorectal preneoplastic lesions.

Experiment 1. A total of 66 male F344 rats were divided into seven groups. Groups 1-5 were initiated with DMH by four weekly s.c. injections ( $40 \mathrm{mg} / \mathrm{kg}$ body weight). Rats in groups 2 and 3 were fed the diet containing 200 and 400 ppm of 6-MSITC, respectively, for 5 weeks, starting 1 week before the first dosing of DMH until the end of week 5. The rats were then switched to and maintained on the basal diet until the termination. Starting 1 week after the cessation of DMH treatment, rats in groups 4 and 5 were fed the diet mixed with 200 and 400 ppm 6-MSITC, respectively, and this was continued until the termination. Rats in group 6 were fed the diet containing 400 ppm 6-MSITC throughout the experiment and group 7 served as the untreated control. At termination, all animals were sacrificed to assess the incidences of ACF and BCAC in the large bowel. Tissues were embedded in paraffin blocks and processed for routine histological observation with hematoxylin and eosin (H\&E) staining.

Identification of ACF. After fixation of resected colons in $10 \%$ buffered formalin for at least $24 \mathrm{~h}$ at room temperature, the colons were stained using $0.5 \%$ methylene blue (in saline) for 1-3 min. After staining, ACF were counted and recorded according to the procedure described by Bird (20). The size of the lesions was scored as crypt multiplicity ( $\mathrm{ACF} /$ lesion). In this study, we divided the colon into three portions after excision of the caecum (proximal, middle and distal) and used all of the segments for the analysis (21).

Identification of BCAC. After ACF counting, colon tissues were embedded in paraffin and processed for immunohistochemistry of BCAC. Briefly, serial sections (4- $\mu \mathrm{m}$ thick) were prepared to include the middle portion between the surface and the bottom of the crypt. Some of these sections were used for immunohistochemistry of $\beta$-catenin and routine $H \& E$ staining. Immunohistochemistry was performed after exposure to $3 \%$ $\mathrm{H}_{2} \mathrm{O}_{2}$ for 20 min to block the endogenous peroxidase activity using a primary antibody to the $\beta$-catenin protein (1:1000 dilution; Transduction Laboratories, Lexington, KY, USA) at room temperature for $60 \mathrm{~min}$. Then, the sections were stained with an LSAB kit (Dako, Glostrup, Denmark).

PCNA immunohistochemistry. To assess the proliferative activity of cells in ACF and BCAC, immunohistochemical staining for PCNA was performed by using anti-PCNA (1:200 dilution) antibody and an LSAB kit (both from Dako). The nuclei that densely immunoreacted with PCNA were regarded as PCNA-positive. PCNA labeling indices were determined by counting the number of positive cells among at least 200 epithelial cells in ACF and BCAC, and were indicated as percentages.

Experiment 2. Nine male F344 rats were divided into three groups. At 6 weeks of age, rats in group 1 were given corn oil through an intragastric tube and served as a control. Animals in groups 2 and 3 were given 6-MSITC at a dose of 20 and 40 $\mathrm{mg} / \mathrm{kg}$ body weight in corn oil using a gastric tube, respectively (equivalent to daily consumption of 6-MSITC at 200 or $400 \mathrm{ppm}$ ). The animals were decapitated $24 \mathrm{~h}$ after the last dose of the vehicle or 6-MSITC. Livers were perfused in situ with ice-cold sterile $1.15 \% \mathrm{KCl}$, and $25 \%$ homogenates in $1.15 \% \mathrm{KCl}$ were prepared. Microsomal fractions from these tissues were prepared using established procedures (22).

Western blot analysis. Gel electrophoresis and blot analysis were carried out as described in detail previously, according to the established methods of Laemmli (23) and Towbin et al (24), respectively. Separated proteins were transferred by semi-dry electroblotting from sodium dodecylsulfatepolyacrylamide gels to polyvinylidene difluoride membranes (Immobilon-P; Millipore, Bedford, MA, USA) in $25 \mathrm{mM}$ Tris buffer ( $\mathrm{pH} 8.3$ ) containing $0.19 \mathrm{M}$ glycine and 20\% (v/v) methanol. The membranes were blocked by incubation with phosphate-buffered saline containing 5\% skim milk for $1 \mathrm{~h}$ before incubation with goat anti-rat polyclonal antibodies for CYP1A1/2, CYP2B1/2, CYP2E1 and CYP3A2 (Daiichi Pure Chemicals, Tokyo, Japan), and then stained using biotinylated anti-goat immunoglobulin $\mathrm{G}$ (Vector Laboratories, Burlingame, CA, USA) using a Wako ABC-POD kit (Wako Pure Chemicals, Osaka, Japan).

Assay of UDPGT activity. UDPGT activity towards bilirubin and 4-nitrophenol in liver microsomes was assayed according to the methods of Heirwegh et al (25) and Isselbacher et al (26), respectively, and towards testosterone with UDP- $\left[{ }^{14} \mathrm{C}(\mathrm{U})\right]$ glucuronic acid, as described by Matern et al 
Table I. Body, liver and kidney weights.

\begin{tabular}{llccc}
\hline Group & Treatment (no. of rats examined) & Body weight (g) & Liver weight (g) & Kidney weight (g) \\
\hline 1 & DMH + basal diet (10) & $319.4 \pm 14.9$ & $10.55 \pm 0.87$ & $2.13 \pm 0.13$ \\
2 & DMH + 200 ppm 6-MSITC (10) & $316.8 \pm 20.4$ & $11.04 \pm 1.13$ & $2.20 \pm 0.19$ \\
3 & DMH + 400 ppm 6-MSITC (10) & $311.3 \pm 17.9$ & $11.24 \pm 0.81$ & $2.21 \pm 0.17$ \\
4 & DMH $\rightarrow$ 200 ppm 6-MSITC (10) & $309.4 \pm 17.8$ & $10.99 \pm 1.45$ & $2.13 \pm 0.13$ \\
5 & DMH $\rightarrow$ 400 ppm 6-MSITC (10) & $307.5 \pm 22.6$ & $11.37 \pm 1.19$ & $2.14 \pm 0.16$ \\
6 & 400 ppm 6-MSITC (8) & $299.5 \pm 14.7$ & $11.37 \pm 0.79$ & $2.16 \pm 0.18$ \\
7 & Basal diet (8) & $315.7 \pm 24.4$ & $11.94 \pm 1.30$ & $2.26 \pm 0.11$ \\
\hline
\end{tabular}

Table II. Effect of 6-MSITC on DMH-induced ACF formation in male F344 rats.

\begin{tabular}{llccc}
\hline Group & \multicolumn{1}{c}{ Treatment } & No. of ACF/colon & No. of ACF $\geq 4$ crypts & No. of crypts/ACF \\
\hline 1 & DMH + basal diet & $323.8 \pm 69.7$ & $155.1 \pm 45.4$ & $3.67 \pm 0.23$ \\
2 & DMH + 200 ppm 6-MSITC & $351.6 \pm 32.8$ & $162.1 \pm 18.7$ & $3.67 \pm 0.17$ \\
3 & DMH + 400 ppm 6-MSITC & $153.9 \pm 62.4^{\mathrm{a}}$ & $65.4 \pm 36.6^{\mathrm{b}}$ & $3.38 \pm 0.24^{\mathrm{c}}$ \\
4 & DMH $\rightarrow 200$ ppm 6-MSITC & $339.3 \pm 80.4$ & $164.1 \pm 45.7$ & $3.70 \pm 0.31$ \\
5 & DMH $\rightarrow 400$ ppm 6-MSITC & $310.0 \pm 55.6$ & $140.3 \pm 18.6$ & $3.61 \pm 0.21$ \\
6 & 400 ppm 6-MSITC & 0 & 0 & 0 \\
7 & Basal diet & 0 & 0 & 0 \\
\hline
\end{tabular}

${ }^{\mathrm{a}}$ Significantly different from group $1\left({ }^{\mathrm{a}} \mathrm{P}<0.0001,{ }^{\mathrm{b}} \mathrm{P}<0.001\right.$ and $\left.{ }^{\mathrm{c}} \mathrm{P}<0.05\right)$.

Table III. Effect of 6-MSITC on DMH-induced BCAC formation in male F344 rats.

\begin{tabular}{llcr}
\hline Group & \multicolumn{1}{c}{ Treatment } & No. of BCAC/cm ${ }^{2}$ & No. of crypts/BCAC \\
\hline 1 & DMH + basal diet & $3.80 \pm 1.05$ & $8.75 \pm 2.04$ \\
2 & DMH + 200 ppm 6-MSITC & $3.47 \pm 1.34$ & $6.87 \pm 1.30^{\mathrm{a}}$ \\
3 & DMH + 400 ppm 6-MSITC & $0.91 \pm 0.58^{\mathrm{b}}$ & $5.01 \pm 1.48^{\mathrm{c}}$ \\
4 & DMH $\rightarrow 200$ ppm 6-MSITC & $3.56 \pm 1.00$ & $8.38 \pm 2.86$ \\
5 & DMH $\rightarrow 400$ ppm 6-MSITC & $3.20 \pm 1.40$ & $6.43 \pm 1.34^{\mathrm{d}}$ \\
6 & 400 ppm 6-MSITC & 0 & 0 \\
7 & Basal diet & 0 & 0 \\
\hline
\end{tabular}

Significantly different from group $1\left({ }^{\mathrm{a}} \mathrm{P}<0.05\right.$, ${ }^{\mathrm{b}} \mathrm{P}<0.00001,{ }^{\mathrm{c}} \mathrm{P}<0.001$ and $\left.\mathrm{d} \mathrm{P}<0.01\right)$.

(27). Each test was carried out with liver microsomes pooled from three rats. Experiments were performed six to eight times, and then the average value was calculated.

Statistical analysis. Data are expressed as the mean \pm SD. The statistical significance of the difference in mean values was analyzed using one-way analysis of variance (ANOVA) and the unpaired t-test. Significance was defined as $\mathrm{P}<0.05$.

\section{Results}

General observation. The rats tolerated s.c. injection of DMH and/or 6-MSITC feeding well. During the study, no clinical signs of toxicity were present in any group. The mean body, liver and kidney weights did not significantly differ among the groups (Table I). Histologically, there were no pathological alterations indicative of toxicity of 6-MSITC in the major organs, such as the liver or kidney.

Inhibitory effects of 6-MSITC on ACF and BCAC. The rats in groups 1-5 developed ACF and BCAC in the colonic mucosa. No such lesions were noted in any of the rats in groups 6 and 7 . In group 1, the frequency of ACF and BCAC were 323.8 $\pm 69.7 /$ colon and $3.80 \pm 1.05 / \mathrm{cm}^{2}$ colonic mucosa, respectively. The number of $\mathrm{ACF} /$ colon was significantly lower in group 3 DMH-treated rats fed a 400 ppm 6-MSITC diet during the 
Table IV. PCNA-labeling index in ACF and BCAC.

\begin{tabular}{llll}
\hline Group & Treatment (no. of rats examined) & ACF & BCAC \\
\hline 1 & DMH + basal diet (5) & $26.8 \pm 9.5$ & $50.6 \pm 10.1$ \\
2 & DMH + 200 ppm 6-MSITC (5) & $21.4 \pm 15.3$ & $39.9 \pm 10.9$ \\
3 & DMH + 400 ppm 6-MSITC (5) & $21.2 \pm 19.1$ & $28.4 \pm 8.4^{\mathrm{a}}$ \\
4 & $\mathrm{DMH} \rightarrow 200$ ppm 6-MSITC (5) & $11.8 \pm 8.6$ & $38.1 \pm 5.1$ \\
5 & $\mathrm{DMH} \rightarrow 400$ ppm 6-MSITC (5) & $11.6 \pm 9.6$ & $36.2 \pm 12.1$ \\
\hline
\end{tabular}

aignificantly different from group $1(\mathrm{P}<0.01)$.

Table V. UDPGT activities in liver microsomes from male F344 rats.

\begin{tabular}{lcccc}
\hline & & \multicolumn{2}{c}{ UDPGT activity (nmol/min/mg protein) } \\
\cline { 3 - 5 } Group & Treatment & 4-Nitrophenol & Bilirubin & Testosterone \\
\hline 1 & Vehicle & $31.2 \pm 5.2$ & $0.18 \pm 0.01$ & $0.12 \pm 0.04$ \\
2 & $20 \mathrm{mg} / \mathrm{kg}$ 6-MSITC & $35.8 \pm 4.7$ & $0.17 \pm 0.02$ & $0.12 \pm 0.02$ \\
3 & $40 \mathrm{mg} / \mathrm{kg}$ 6-MSITC & $31.4 \pm 2.7$ & $0.17 \pm 0.01$ & $0.13 \pm 0.05$ \\
\hline
\end{tabular}

initiation phase than that in rats treated with DMH alone (group 1) $(153.9 \pm 62.4,52 \%$ reduction, $\mathrm{P}<0.0001$; Table II). The reduction was also significant for the larger ACF with $\geq 4$ crypts: from 155.1 to 65.4 (58\% reduction, $\mathrm{P}<0.001$; Table II, group 3 vs. group 1). In group 3, 400 ppm 6-MSITC also caused a significant decrease in the mean number of $\mathrm{BCAC} /$ $\mathrm{cm}^{2}$ colon when compared with the control rats in group 1 $(0.91 \pm 0.58,76 \%$ reduction, $\mathrm{P}<0.00001$; Table III). Thus, both $\mathrm{ACF}$ and BCAC were reduced to approximately the same extent. Regarding crypt multiplicity, a significant decrease in the number of crypts/lesion in group 3 was found in both $\mathrm{ACF}$ and $\mathrm{BCAC}$ when compared with that in group $1(\mathrm{P}<0.05$ and $\mathrm{P}<0.001$, respectively). The number of crypts/BCAC in groups $2(\mathrm{DMH}+200 \mathrm{ppm} 6-\mathrm{MSITC})$ and $5(\mathrm{DMH} \rightarrow 400 \mathrm{ppm}$ 6 -MSITC) were smaller than those in group 1, with a statistical significance of $\mathrm{P}<0.05$ and $\mathrm{P}<0.01$, respectively.

Inhibition of the PCNA labeling index in ACF and BCAC. In group 3, treatment of rats with $400 \mathrm{ppm}$ levels of 6-MSITC resulted in a significant decrease in the labeling index of PCNA in BCAC when compared to group 1 treated with DMH alone $(\mathrm{P}<0.01$; Table IV). The mean PCNA labeling indices of groups 4 and 5 in ACF were lower than group 1, but the differences did not reach statistical significance.

Determination of CYP isoforms in the liver. Fig. 1 shows immunoblots and levels of liver microsomal CYP proteins in male F344 rats $24 \mathrm{~h}$ after 6-MSITC treatment. Neither hepatic CYP2B1 nor CYP1A1 were constitutively expressed. Treatment with $40 \mathrm{mg} / \mathrm{kg}$ b.w. 6-MSITC significantly decreased CYP1A2, -2B2, -2E1 and -3A2 proteins by 20 , 35,44 and $20 \%$, respectively, relative to the vehicle group. Exposure to $20 \mathrm{mg} / \mathrm{kg}$ b.w. 6-MSITC also significantly

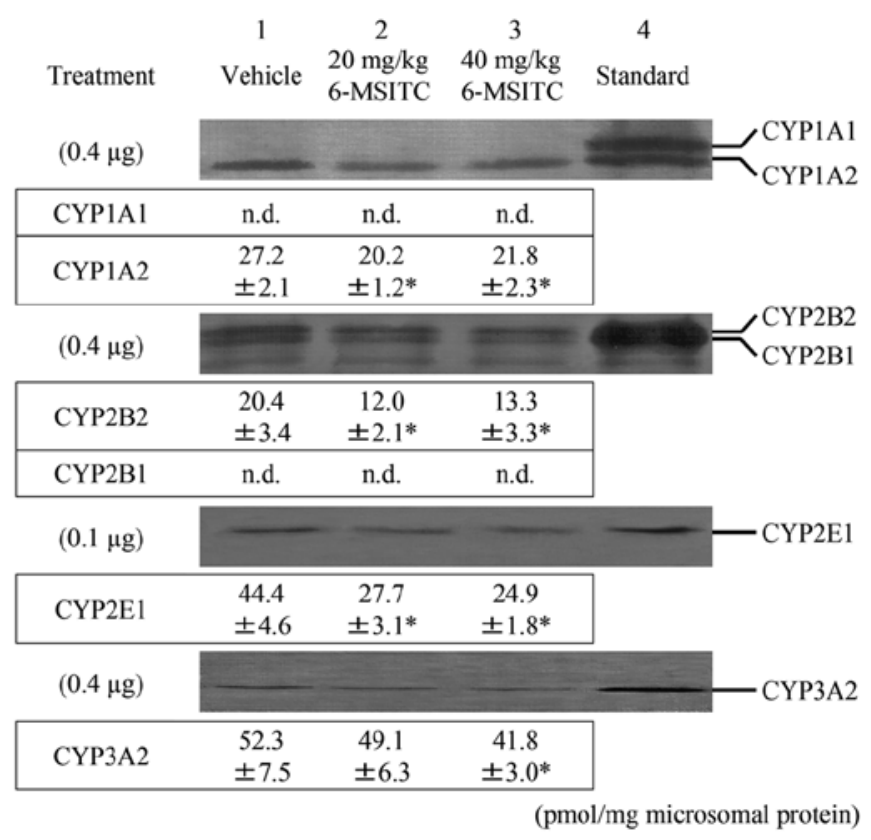

Figure 1. Immunoblots and densitometric determination of the expression of CYP protein in liver microsomes from rats treated with 6-MSITC. Lane 4 contains CYP standards from rats treated with 3-methylcholanthrene (CYP1A1/2), phenobarbital (CYP2B1/2 and -3A2) and acetone (CYP2E1). Liver microsomes were pooled from three rats and contained 0.4 and $0.1 \mu \mathrm{g}$ microsomal proteins. The values represent the mean $\pm \mathrm{SD}$ of $\mathrm{pmol} / \mathrm{mg}$ microsomal protein obtained from six to eight experiments. ${ }^{*} \mathrm{P}<0.01$; significant differences obtained by comparison with the vehicle control group. n.d., not detected.

decreased hepatic CYP1A2, -2B2 and -2E1 protein levels when compared to group 1.

Hepatic UDPGT activity. Table V summarizes the effects of 6-MSITC treatment on hepatic UDPGT activity towards 
4-nitrophenol, bilirubin and testosterone in liver microsomes. No significant differences were noted among the three groups.

\section{Discussion}

In this study, the modulating effects of 6-MSITC on colonic $\mathrm{ACF}$ and $\mathrm{BCAC}$ formation were proven by their exposure at the initiation and promotion phases in rats. ACF have been widely used as intermediate biomarkers of colon carcinogenesis in experimental animal models, and a positive correlation has been described between the effects of chemopreventive agents on ACF and tumor development (28). It is likely that larger ACF ( $\geq 4$ crypts/lesion) are histogenetically close to dysplastic adenomas in order for adenomas to be more appropriate biomarkers (29,30). BCAC, another mucosal lesion, was evaluated in the present bioassay as a surrogate biomarker of colon carcinogenesis. Our previous results indicated that $\mathrm{BCAC}$ are more sensitive and more reliable than $\mathrm{ACF}$ as intermediate biomarkers of colon carcinogenesis $(31,32)$. Significantly, ACF and BCAC are considered to be independent and distinct, as they differ in biology, genetics and morphology $(31,33,34)$. In this context, the present result that 6-MSITC inhibited the formation of two different lesions can be regarded as convincing. Furthermore, rats fed the diets containing 6-MSITC showed no adverse effects and no clinical signs of toxicity. Collectively, these findings suggest that 6-MSITC is a new chemopreventive agent against colon cancer development.

Several explanations for the inhibitory effects of 6-MSITC on ACF and BCAC formation by DMH were considered. Cell proliferation has long been suspected to play a significant role in the initiation step as well as the promotion of carcinogenesis (35). In the current study, we found that 6-MSITC inhibited proliferation of epithelial cells in ACF and BCAC. A previous study showed that 6-MSITC inhibited the growth of MCF-7 human breast cancer and LOX-IMVI human melanoma cell lines (17). Thus, the inhibitory effect of 6-MSITC may be, in part, due to the modification of cell proliferation activity in cryptal cells.

Data on the incidence and crypt multiplicity of colonic preneoplastic lesions indicated that a 6-MSITC feeding together with or after DMH exposure was able to inhibit colonic tumorigenesis, the suppression of dietary 6-MSITC during the initiation phase being more effective. This is in accordance with the previous findings for a 6-MSITC inhibition of chemically induced carcinogenesis (36), and the theory that the compound should be viewed as a 'blocking' agent against colon carcinogenesis (37). Regarding mechanisms, 'blocking' compounds generally have a capacity to induce phase II detoxification enzymes and/or inhibit phase I enzymes that are required for the bioactivation of carcinogens (38). It has also been reported that ITCs function by blocking the initiation phase in part via inhibition of phase I enzymes and/or induction of phase II enzymes (10-13). This may be the case with 6-MSITC, since it decreased hepatic CYP1A2, -2B2, -2E1 and $-3 \mathrm{~A} 2$ by $7-44 \%$, compared with the vehicle control. It is generally accepted that CYPs are known to play a prominent role in the biotransformation of carcinogenic xenobiotics. In the rat, hepatic CYP1A1/2,
CYP2B1/2 and CYP3A2 were reported to contribute to the mutagenic activation of heterocyclic amines, benzo[a]pyrene and aflatoxins $(39,40)$. CYP2B1/2 and -2E1 are also specifically involved in the metabolic activation of environmental $N$-nitrosamines to ultimate carcinogens $(41,42)$. Furthermore, CYP2E1 is one of the enzymes catalyzing the conversion of azoxymethane and methylazoxymethanol, which are metabolites of DMH, to DNA alkylating species capable of causing initiation events $(43,44)$. In this context, decreased levels of CYPs by 6-MSITC were expected to result in the reduction and/or slowing of the transformation of metabolites of DMH to proximate or ultimate carcinogens. On the other hand, 6-MSITC did not significantly alter the UDPGT activity towards bilirubin, 4-nitrophenol and testosterone in hepatic microsomes. Glucuronidation is generally considered to be one of the detoxification reactions in the metabolism of various chemicals including carcinogens. UDPGT1A1 (for bilirubin), UDPGT1A6 (for 4-nitrophenol) and UDPGT2B1 (for testosterone) are found as major enzymes in the liver, and are responsible for the glucuronidation reaction. In a previous study, we showed that certain carcinogenic compounds are substrates for the enzymes (45). However, the present findings showed that hepatic UDPGT activity was not involved in 6-MSITC modification.

In conclusion, the results described herein demonstrate that the dietary administration of 6-MSITC can significantly inhibit the induction of colonic ACF and BCAC by DMH, by reducing cell proliferative activity and the protein levels of phase I enzymes.

\section{Acknowledgements}

We appreciate the technical assistance of Ms. K. Takahashi, the secretarial assistance of Ms. S. Gotou and the animal care given by Mr. Y. Kinjou. This work was supported by Grantsin-Aid from the Ministry of Education, Culture, Sports, Science and Technology and the Ministry of Health, Labor and Welfare of Japan.

\section{References}

1. Parkin DM, Bray F, Ferlay J and Pisani P: Global cancer statistics, 2002. CA Cancer J Clin 55: 74-108, 2005.

2. Willett W: The search for the causes of breast and colon cancer. Nature 338: 389-394, 1989.

3. Hebert JR, Landon J and Miller DR: Consumption of meat and fruit in relation to oral and esophageal cancer: a cross-national study. Nutr Cancer 19: 169-179, 1993.

4. Block G, Patterson B and Subar A: Fruit, vegetables and cancer prevention: a review of the epidemiological evidence. Nutr Cancer 18: 1-29, 1992.

5. Boyle P, Zaridze DG and Smans M: Descriptive epidemiology of colorectal cancer. Int J Cancer 36: 9-18, 1985.

6. Lin HJ, Probst-Hensch NM, Louie AD, et al: Glutathione transferase null genotype, broccoli and lower prevalence of colorectal adenomas. Cancer Epidemiol Biomarkers Prev 7: 647-652, 1998.

7. Hecht SS: Chemoprevention by isothiocyanates. J Cell Biochem Suppl 22: 195-209, 1995.

8. Munday R, Mhawech-Fauceglia P, Munday CM, et al: Inhibition of urinary bladder carcinogenesis by broccoli sprouts. Cancer Res 68: 1593-1600, 2008.

9. Higdon JV, Delage B, Williams DE and Dashwood RH: Cruciferous vegetables and human cancer risk: epidemiologic evidence and mechanistic basis. Pharmacol Res 55: 224-236, 2007. 
10. Leonard TB, Popp JA, Graichen ME and Dent JG: alphaNaphthylisothiocyanate induced alterations in hepatic drug metabolizing enzymes and liver morphology: implications concerning anticarcinogenesis. Carcinogenesis 2: 473-482, 1981.

11. Guo Z, Smith TJ, Wang E, Eklind KI, Chung FL and Yang CS Structure-activity relationships of arylalkyl isothiocyanates for the inhibition of 4-(methylnitrosamino)-1-(3-pyridyl)-1-butanone metabolism and the modulation of xenobiotic-metabolizing enzymes in rats and mice. Carcinogenesis 14: 1167-1173, 1993.

12. Zhang Y and Talalay P: Anticarcinogenic activities of organic isothiocyanates: chemistry and mechanisms. Cancer Res 54: S1976-S1981, 1994.

13. Guo Z, Smith TJ, Wang E, et al: Effects of phenethyl isothiocyanate, a carcinogenesis inhibitor, on xenobiotic-metabolizing enzymes and nitrosamine metabolism in rats. Carcinogenesis 13 : 2205-2210, 1992.

14. Kinae N, Masuda H, Shin IS, Furugori $M$ and Shimoi K: Functional properties of wasabi and horseradish. Biofactors 13: 265-269, 2000

15. Morimitsu Y, Hayashi K, Nakagawa Y, Horio F, Uchida K and Osawa T: Antiplatelet and anticancer isothiocyanates in Japanese domestic horseradish, wasabi. Biofactors 13: 271-276, 2000.

16. Watanabe M, Ohata M, Hayakawa S, et al: Identification of 6-methylsulfinylhexyl isothiocyanate as an apoptosis-inducing component in wasabi. Phytochemistry 62: 733-739, 2003

17. Nomura T, Shinoda S, Yamori T, et al: Selective sensitivity to wasabi-derived 6-(methylsulfinyl)hexyl isothiocyanate of human breast cancer and melanoma cell lines studied in vitro. Cancer Detect Prev 29: 155-160, 2005.

18. Morimitsu Y, Nakagawa Y, Hayashi K, et al: A sulforaphane analogue that potently activates the Nrf2-dependent detoxification pathway. J Biol Chem 277: 3456-3463, 2002.

19. Thimmulappa RK, Mai KH, Srisuma S, Kensler TW Yamamoto $\mathrm{M}$ and Biswal S: Identification of Nrf2-regulated genes induced by the chemopreventive agent sulforaphane by oligonucleotide microarray. Cancer Res 62: 5196-5203, 2002.

20. Bird RP: Observation and quantification of aberrant crypts in the murine colon treated with a colon carcinogen: preliminary findings. Cancer Lett 37: 147-151, 1987.

21. Yamada Y, Yoshimi N, Hirose Y, et al: Suppression of occurrence and advancement of beta-catenin-accumulated crypts, possible premalignant lesions of colon cancer, by selective cyclooxygenase-2 inhibitor, celecoxib. Jpn J Cancer Res 92: 617-623, 2001.

22. Mori Y, Yamazaki H, Toyoshi K, et al: Mutagenic activation of carcinogenic N-nitrosopropylamines by rat liver: evidence for a cytochrome P-450-dependent reaction. Carcinogenesis 6 : 415-420, 1985

23. Laemmli UK: Cleavage of structural proteins during the assembly of the head of bacteriophage T4. Nature 227: 680-685, 1970.

24. Towbin H, Staehelin T and Gordon J: Electrophoretic transfer of proteins from polyacrylamide gels to nitrocellulose sheets: procedure and some applications. Proc Natl Acad Sci USA 76: 4350-4354, 1979

25. Heirwegh KP, van de Vijver M and Fevery J: Assay and properties of dititonin-activated bilirubin uridine diphosphate glucuronyltransferase from rat liver. Biochem J 129: 605-618, 1972.

26. Isselbacher KJ, Chrabas MF and Quinn RC: The solubilization and partial purification of a glucuronyl transferase from rabbit liver microsomes. J Biol Chem 237: 3033-3036, 1962.

27. Matern H, Heinemann $\mathrm{H}$ and Matern S: Radioassay of UDP-glucuronosyltransferase activities toward endogenous substrates using labeled UDP-glucuronic acid and an organic solvent extraction procedure. Anal Biochem 219: 182-188, 1994.
28. Corpet DE and Tache S: Most effective colon cancer chemopreventive agents in rats: a systematic review of aberrant crypt foci and tumor data, ranked by potency. Nutr Cancer 43: 1-21, 2002.

29. Corpet DE, Stamp D, Medline A, Minkin S, Archer MC and Bruce WR: Promotion of colonic microadenoma growth in mice and rats fed cooked sugar or cooked casein and fat. Cancer Res 50: 6955-6958, 1990.

30. Pretlow TP, O'Riordan MA, Somich GA, Amini SB and Pretlow TG: Aberrant crypts correlate with tumor incidence in F344 rats treated with azoxymethane and phytate. Carcinogenesis 13: 1509-1512, 1992.

31. Yamada Y, Yoshimi N, Hirose Y, et al: Sequential analysis of morphological and biological properties of beta-cateninaccumulated crypts, provable premalignant lesions independent of aberrant crypt foci in rat colon carcinogenesis. Cancer Res 61: 1874-1878, 2001.

32. Hirose Y, Kuno T, Yamada Y, et al: Azoxymethane-induced betacatenin-accumulated crypts in colonic mucosa of rodents as an intermediate biomarker for colon carcinogenesis. Carcinogenesis 24: 107-111, 2003.

33. Yamada Y, Yoshimi N, Hirose Y, et al: Frequent beta-catenin gene mutations and accumulations of the protein in the putative preneoplastic lesions lacking macroscopic aberrant crypt foci appearance, in rat colon carcinogenesis. Cancer Res 60: 3323-3327, 2000

34. Yamada Y, Oyama T, Hirose Y, et al: beta-Catenin mutation is selected during malignant transformation in colon carcinogenesis. Carcinogenesis 24: 91-97, 2003.

35. Cohen SM and Ellwein LB: Cell proliferation in carcinogenesis. Science 249: 1007-1011, 1990.

36. Yano T, Yajima S, Virgona N, et al: The effect of 6-methylthiohexyl isothiocyanate isolated from Wasabia japonica (wasabi) on 4-(methylnitrosamino)-1-(3-pyridyl)-1-buatnone-induced lung tumorigenesis in mice. Cancer Lett 155: 115-120, 2000.

37. Surh YJ: Cancer chemoprevention with dietary phytochemicals. Nat Rev Cancer 3: 768-780, 2003.

38. Myzak MC and Dashwood RH: Chemoprotection by sulforaphane: keep one eye beyond Keap1. Cancer Lett 233: 208-218, 2006.

39. Mori Y, Koide A, Fuwa K and Kobayashi Y: N-benzylimidazole for preparation of $\mathrm{S} 9$ fraction with multi-induction of metabolizing enzymes in short-term genotoxicity assays. Mutagenesis 16: 479-486, 2001.

40. Degawa M, Ueno H, Miura S, Ohta A and Namiki M: A simple method for assessment of rat cytochrome P-448 isozymes responsible for the mutagenic activation of carcinogenic chemicals. Mutat Res 203: 333-338, 1988.

41. Mori Y, Tatematsu K, Koide A, Sugie S, Tanaka T and Mori H: Modification by curcumin of mutagenic activation of carcinogenic N-nitrosamines by extrahepatic cytochromes P-450 2B1 and 2E1 in rats. Cancer Sci 97: 896-904, 2006.

42. Mori Y, Koide A, Kobayashi Y, Morimura K, Kaneko M and Fukushima S: Effect of ethanol treatment on metabolic activation and detoxification of esophagus carcinogenic N-nitrosamines in rat liver. Mutagenesis 17: 251-256, 2002.

43. Sohn OS, Ishizaki H, Yang CS and Fiala ES: Metabolism of azoxymethane, methylazoxymethanolandN-nitrosodimethylamine by cytochrome P450IIE1. Carcinogenesis 12: 127-131, 1991.

44. Sohn OS, Fiala ES, Requeijo SP, Weisburger JH and Gonzalez FJ: Differential effects of CYP2E1 status on the metabolic activation of the colon carcinogens azoxymethane and methylazoxymethanol. Cancer Res 61: 8435-8440, 2001.

45. Mori Y, Takahashi H, Yamazaki H, et al: Distribution, metabolism and excretion of $\mathrm{N}$-nitrosobis(2-hydroxypropyl)amine in Wistar rats. Carcinogenesis 5: 1443-1447, 1984. 